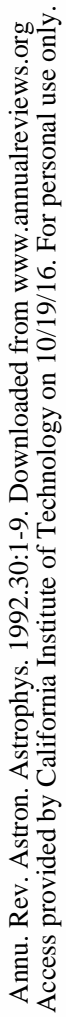

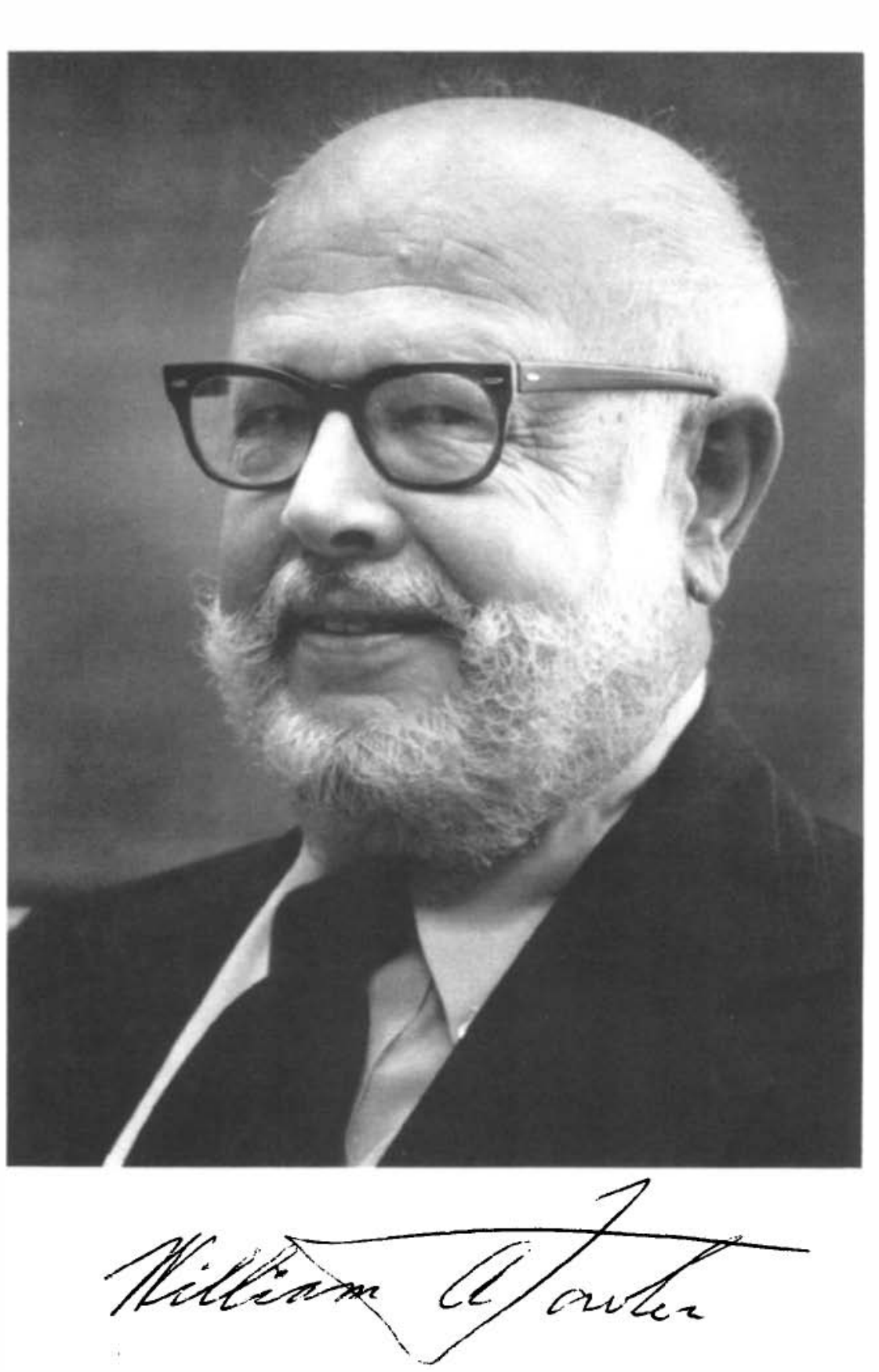




\title{
FROM STEAM TO STARS TO THE EARLY UNIVERSE
}

\author{
William A. Fowler \\ Division of Physics, Mathematics, and Astronomy, California Institute of \\ Technology, Pasadena, California 91125
}

KEY WORDS: inhomogeneous nucleosynthesis, early universe, primordial CNO abundances, old globular clusters

\section{FROM PITTSBURGH TO LIMA TO CALIFORNIA}

Much of what follows was first published in Les Prix Nobel en 1983 (Fowler 1984). I have updated the autobiographical material to the summer of 1991. I was born in 1911 in Pittsburgh, Pennsylvania, the son of John MacLeod Fowler and Jennie Summers Watson Fowler. My parents had two other children, my younger brother, Arthur Watson Fowler and my still younger sister, Nelda Fowler Wood. My paternal grandfather, William Fowler, was a coal miner in Slammannan, near Falkirk, Scotland who emigrated to Pittsburgh to find work as a coal miner around 1880. My maternal grandfather, Alfred Watson, was a grocer. He emigrated to Pittsburgh, also around 1880, from Taniokey, near Clare in County Armagh, Northern Ireland. His parents taught in the National School, the local grammar school for children, in Taniokey, for sixty years. The family lived in the central part of the school building; my great grandfather taught the boys in one wing of the building and my great grandmother taught the girls in the other wing. The school is still there and I have been to see it. I have also visited Slammannan.

I was raised in Lima, Ohio from the age of two when my father, an accountant, was transferred to Lima from Pittsburgh. Each summer during my childhood the family went back to Pittsburgh during my father's vacation from work. He was an ardent sportsman and through him I became (and still am) a loyal fan of the Pittsburgh Pirates in the National 
Baseball League and of the Pittsburgh Steelers in the National Football League.

Lima was a railroad center served by the Pennsylvania, Erie, Nickel Plate, and Baltimore \& Ohio railroads. It was also the home of the Lima Locomotive Works which built steam locomotives. My brother, Arthur Watson Fowler, a mechanical engineer, worked for Lima Locomotive all his life until his retirement. After 1960 the company produced power shovels and construction cranes.

As a boy I spent many hours in the switchyards of the Pennsylvania Railroad not far from my family home. It is no wonder that I go around the world seeking passenger trains still pulled by steam locomotives. In 1973 I traveled the Trans-Siberian Railroad from Khabarovsk to Moscow because, among other reasons, the train was powered by steam for almost 2500 kilometers from Khabarovsk to Chita. It's not powered by steam any longer but now I can afford to ride on the new Orient Express which makes up in luxury what it lacks in steam. It is also no wonder that on my 60th birthday my colleagues and former students presented me in Cambridge, England with a working model, $3 \frac{1}{4}$ " gauge (1/16 standard size) British Tank Engine. I operated it frequently on the elevated track of the Cambridge and District Model Engineering Society. It is my pride and joy. I have named it Prince Hal.

I attended Horace Mann Grade School and Lima Central High School. A few of my high school teachers were still alive when I met them at my 50th class reunion in 1979. I was President of the Senior Class of 1929. My teachers encouraged and fostered my interest in engineering and science. R. W. "Pop" Edmiston taught physics. H. W. "Cappy" Scheurman taught chemistry. Mary Nolan taught algebra and Blanche Andrews taught advanced algebra. E. A. Hauenstein taught mechanical drawing. I still have the set of drawing instruments, compasses, and drawing pens, which I used in Hauenstein's class.

My family home was located across the street from the extensive playgrounds of Horace Mann School. There were baseball diamonds, tennis courts, a running track, and a football field. During my high school days I played on the Central High School football team and won my letter as a senior. Horace Mann was Central's home football field. During my college days I served as Recreational Director of the Horace Mann playground during the summer. Not far from my home was Baxter's Woods with a running creek and swimming hole. What a wonderful environment it all was for my boyhood!

On graduation from high school I enrolled at the Ohio State University in Columbus, Ohio in ceramic engineering. I had won a prize for an essay on the production of Portland cement and ceramic engineering seemed a 
natural choice for me. Fortunately all engineering students took the same coursesincluding physics and mathematics. I became fascinated with physics and when I learned from Professor Alpheus Smith, head of the Physics Department, that there was a new degree offered in Engineering Physics I enrolled in that option at the start of my sophomore year. So also did Leonard I. Schiff, who became a very great theoretical physicist. We were lifelong friends until his death a few years ago.

My parents were not affluent and my summer salary as recreation director did not cover my expenses at Ohio State. For my meals I waited table, washed the dishes, and stoked the furnaces at the Phi Sigma Sigma Sorority. I worked Saturdays cutting and selling ham and cheese in an outside stall at the Central Market in Columbus. Early in the morning we put up the stall and unloaded the hams and cheeses from the wholesaler's truck; late at night we cleaned up and took down the stall. For eighteen hours work I was paid five dollars. I did scrape enough money together to join a social fraternity, Tau Kappa Epsilon. In my junior year I was elected to the engineering honorary society, Tau Beta $\mathrm{Pi}$, and in my senior year I was elected President of the Ohio State Chapter.

My professors at Ohio State encouraged my interest in experimental physics. Alva Smith gave me extra time in the physics laboratory for seniors. Willard Bennett permitted me to do an undergraduate thesis on the "Focussing of Electron Beams" in his laboratory. From him I learned how different a working laboratory is from a student laboratory. The answers were not known! John Byrne permitted me to work after school hours in the electronic laboratory of the Electrical Engineering Department. I studied the characteristics of the pentode! It was the best of worlds - the thrills of making real measurements in physics along with practical training in engineering.

On graduation from Ohio State I came to Caltech and became a graduate student under Charles Christian Lauritsen - physicist, engineer, architect, and violinist - in the W. K. Kellogg Radiation Laboratory. Kellogg was constructed to Lauritsen's architectural plans by funds obtained from the American cornflakes king by Robert Andrews Millikan. Lauritsen was a native of Denmark and in common with many Scandinavians he loved the songs of Carl Michael Bellman, the 18th century Swedish poet-musician. He tried to teach me to sing Bellman's drinking songs with a good Swedish accent but I failed miserably except in spirit - or should I say spirits.

Charlie Lauritsen was the greatest influence in my life. He supervised my doctoral thesis on "Radioactive Elements of Low Atomic Number" in which we discovered mirror nuclei and showed that the nuclear forces are charge symmetric - the same between two protons as between two neutrons when charged particle Coulomb forces are excluded. He taught 
me many practical things - how to repair motors, plumbing, and electrical wiring. Most of all he taught me how to do physics and how to enjoy it. I also learned from my fellow graduate students Richard Crane and Lewis Delsasso. Charlie's son, Tommy Lauritsen, did his doctoral work under us and the three of us worked together as a team for over thirty-five years. We were primarily experimentalists. In the early days Robert Oppenheimer taught us the theoretical implications of our results. Richard Tolman taught us not to rush into the publication of premature results in those days of intense competition between nuclear laboratories. "Del" Delasso dubbed me "Willy" and it stuck!

Hans Bethe's announcement of the CN-cycle in 1939 changed our lives. We were studying the nuclear reactions of protons with the isotopes of carbon and nitrogen in the laboratory, the very reactions in the $\mathrm{CN}$-cycle. World War II intervened. The Kellogg Laboratory was engaged in defense research throughout the war. I spent three months in the South Pacific during 1944 as a civilian with simulated military rank. I saw at first hand the heroism of soldiers and seamen and the horrors they endured.

Just before the war I married Ardiane Foy Olmsted whose family came to California over the plains and mountains of the western United States in the Gold Rush of 1849. We became the parents of two daughters, Mary Emily and Martha Summers, whom we referred to as our biblical characters. Martha and her husband, Robert Schoenemann, are the parents of my grandson, Spruce William Schoenemann. They live in Pawlet, a small village in Vermont - the Green Mountain State.

After the war the Lauritsens and I restored Kellogg as a nuclear laboratory and decided to concentrate on those nuclear reactions that take place in stars. We called it Nuclear Astrophysics. Before the war Hans Staub and William Stephens had confirmed in Kellogg that there was no stable nucleus at mass 5 . After the war Alvin Tollestrup, Charlie Lauritsen, and I confirmed that there was no stable nucleus at mass 8 . These mass gaps spelled the doom of George Gamow's brilliant idea that all nuclei heavier than helium (mass 4) could be built by neutron addition, one mass unit at a time in his big bang. Edwin Salpeter of Cornell came to Kellogg in the summer of 1951 and showed that the fusion of three helium nuclei of mass 4 into the carbon nucleus of mass 12 could occur in red giant stars but not in the big bang. In 1953 Fred Hoyle induced Ward Whaling at Kellogg to perform an experiment which quantitatively confirmed the fusion process under the temperature and density conditions that Hoyle, Martin Schwarzschild, and Allan Sandage had shown occur in red giants stars.

Fred Hoyle was the second great influence in my life. The grand concept of nucleosynthesis in stars originated with Hoyle as early as 1946. After 
Whaling's confirmation of Hoyle's ideas I became a believer and in 1954/ 1955 spent a sabbatical year in Cambridge, England as a Fulbright Scholar in order to work with Hoyle. There Geoffrey and Margaret Burbidge joined us. In 1956 the Burbidges and Hoyle came to Kellogg, and in 1957 our joint efforts culminated in the publication of "Synthesis of the Elements in Stars" in which we showed that all of the elements from carbon to uranium could be produced by nuclear processes in stars starting with the hydrogen and helium produced in the big bang. This paper has come to be known from the last initials of the authors as $B^{2} F H$. A. G. W. Cameron single-handedly came forward with the same broad ideas at the same time.

Fred Hoyle became the Plumian Professor at Cambridge, was knighted by the Queen, and founded the Institute of Theoretical Astronomy in Cambridge in 1966. I spent many happy summers at the Institute until Hoyle's retirement to Cumbria in the Lake District of England. Fred taught me more than astrophysics. He introduced me to English cricket, rugby, and association football (we call it soccer). He took me to the Scottish Highlands and taught me how to read an ordnance map as well as how to enjoy climbing the $3000 \mathrm{ft}$ peaks called Munros. I still go climbing somewhere in the British Isles every summer. It keeps me fit and renews my soul.

Ardiane Fowler died in May of 1988. In December 1989 I married Mary Dutcher of Flushing, Long Island. Mary Dutcher had taught in grade schools on Long Island for more than forty years and had not previously been married. One of her ancestors was John Lothropp (1584-1653) who, after matriculation in Queen's College, University of Cambridge, in 1601, became the curate in charge of Egerton Church in Kent, forty-eight miles southeast of London. In 1623 Lothropp left the Church of England and subscribed to the teachings of the Separatist or Congregational Church. In 1633, Charles I elevated Bishop William Laud to Archbishop of Canterbury. Laud determined to impose a uniform system of worship on all Englishmen and incarcerated Lothropp until 1634 when he was released from prison on bail. Lothropp petitioned for liberty to go into foreign exile and came to New England where he settled in Scituate, Massachusetts and became pastor of the Puritan church in that village. He eventually settled in Barnstable, Massachusetts where the Sturgis Library houses the Lothropp Bible and part of John Lothropp's original house. In the summer of 1990 Mary Dutcher Fowler and I visited the parish of Lowthorpe in the East Riding of Yorkshire, where John Lothropp was born: At the parish church we were able to see the many family Lothropp items that have been collected and preserved there. We eventually obtained the biography of John Lothropp published by Richard W. Price and Associates, Salt Lake City, Utah, in 1989. 
Now, Mary Dutcher Fowler and I reside in the two-story, New England style white frame house, which I purchased in 1958. It is only a ten minute walk from Caltech. I am retired from teaching so my only routine trips to the Institute are on Wednesdays for the Astronomy Seminar, Thursdays for the Physics Seminar, and on Fridays for the Kellogg Nuclear Physics Seminar. Mary Dutcher Fowler has painted all her life and she now attends a painting school in Pasadena. We keep busy, take long walks many weekends, and in general try to stay out of trouble.

It is appropriate to conclude this section, without elaboration, with details of my life outside the laboratory:

Awarded Medal for Merit by President Harry Truman, 1948; elected member of the National Academy of Sciences, 1956; awarded Barnard Medal for Meritorious Service to Science, 1965; member of the National Science Board, 1968-74; member of the Space Science Board, 1970-73, 1977-80; designated Benjamin Franklin Fellow of the Royal Society of Arts, 1970; awarded the G. Unger Vetlesen Prize, 1973; awarded National Medal of Science by President Gerald Ford, 1974; designated Associate of the Royal Astronomical Society, 1975; elected President of the American Physical Society, 1976; designated an Honorary Member of the Mark Twain Society, 1976; awarded Eddington Medal of the Royal Astronomical Society, 1978; Awarded Bruce Gold Medal, Astronomical Society of the Pacific, 1979; elected to the Society of American Baseball Research (1980); honorary degrees awarded by University of Chicago 1976, Ohio State University 1978, University of Liège 1981, Observatory of Paris 1981, Denison University 1982, Arizona State University 1985, Georgetown University 1986, University of Massachusetts 1987, Williams College 1988, and Gustavus Adolphus College 1991; Nobel Prize for Physics, 1983; Sullivant Medal, The Ohio State University, 1985; first recipient of the William A. Fowler Award for Excellence and Distinguished Accomplishments in Physics, Ohio Section, American Physical Society, 1986; Legion d'Honneur awarded by President Mitterand of France, 1989; member Lima City Schools Distinguished Alumni Hall of Fame, 1990; member Ohio Sci. \& Tech. Hall of Fame, 1991.

\section{NUCLEOSYNTHESIS IN THE EARLY UNIVERSE}

It is well established that the youngest, latest stars in our Galaxy, the Milky Way, have abundances of the elements carbon, oxygen, and heavier, which were produced by stellar nucleosynthesis in older, earlier Galactic stars. However, there is some controversy concerning the origin of these heavy elements which are observed in small amounts, but not zero, in the 
oldest Galactic stars. These oldest Galactic stars reside in the halo of the Galaxy and have heavy element abundances relative to that of the sun of the order of 0.1 on the average. In this contribution I take the view that some of the chemical elements in thc halo were produced in the inflationary inhomogeneous stage of the early universe. This view is expressed in considerable detail in Kawano et al (1991). What follows is a modified version of that article.

Ever since the pioneering work of Applegate \& Hogan (1985), there has been keen interest and fruitful research in the study of inhomogeneous nucleosynthesis. In this model of nucleosynthesis, density fluctuations produced in the very early quark-hadron phase transition lead to the formation of two distinct regions: a high-density region (which made a late transition from the quark state to the hadron state) and a low-density region (which made the transition earlier). The environment is thus characterized by the fractional volume of each region and the density contrast between the two regions. The mean baryon density in the universe, $\Omega_{b}$, is given as the weighted sum of the densities of the high-density region and low-density region. For $\Omega_{\mathrm{b}}=1$, the baryon density is equal to the critical density separating an open universe from a closed universe.

Once these high-density and low-density regions are formed, however, the density inhomogeneities are soon characterized by a chemical inhomogeneity as neutrons stream out of the high-density regions because of their relatively long mean-free-path (compared with the length scale of the highdensity regions). Thus, the high-density regions become proton-rich and the low-density regions become neutron-rich.

The two regions, each characterized by its own baryon density and neutron mass fraction, undergo a standard homogeneous nucleosynthesis so that to obtain the total elemental abundances produced, one averages over the resulting mass fractions in each region. This is a considerable oversimplification but suffices as a fair approximation. The authors of the original papers made the claim that the averaged abundances so obtained for $\Omega_{\mathrm{b}}=1$ were within observational bounds for the inferred primordial abundances for $\mathrm{D},{ }^{3} \mathrm{He}$, and ${ }^{4} \mathrm{He}$ (the computed abundances for ${ }^{7} \mathrm{Li}$ came out somewhat high) so that baryonic nucleosynthesis could be reconciled with a universe of critical density. Moreover, Malaney \& Fowler (1988) pointed out that late-time diffusion of ncutrons back into the high-density regions could reduce the amount of lithium produced to an acceptable level if the diffusion was late enough (so as not to perturb the other light elements). In a later paper (Malaney \& Fowler 1989) they showed that ${ }^{9} \mathrm{Be}$ is produced in abundances matching those observed in the earliest, oldest stars in the Galaxy. 
Besides the possibility of having $\Omega_{\mathrm{b}}=1$, there was the prospect that inhomogeneous nucleosynthesis might provide significant primordial abundances of $\mathrm{CNO}$ isotopes. It was determined that the bulk of the CNO production came through the ${ }^{7} \operatorname{Li}(n, \gamma){ }^{8} \operatorname{Li}(\alpha, n){ }^{11} \mathrm{~B}(n, \gamma){ }^{12} \mathrm{~B}\left(e^{-} v\right)^{12} \mathrm{C}$ etc, etc reaction sequence in the neutron-rich region. Kawano et al (1991) followed up this suggestion and looked at a more detailed reaction sequence for a wider range of parameters than hitherto studied, examining the relative importance of the ${ }^{7} \mathrm{Li}(n, \gamma)^{8} \mathrm{Li}$ reaction and the ${ }^{7} \mathrm{Li}(\alpha, \gamma)^{11} \mathrm{~B}$ reaction in the production of CNO elements. They also examined the path of heavyelement production at ${ }^{14} \mathrm{C}$, looking at the relative importance of the ${ }^{14} \mathrm{C}(n, \gamma){ }^{15} \mathrm{C}$ and ${ }^{14} \mathrm{C}(p, \gamma){ }^{15} \mathrm{~N}$ reactions as well as the ${ }^{14} \mathrm{C}(d, n){ }^{15} \mathrm{~N}$ reaction which was included for the first time.

These investigations of $\mathrm{CNO}$ elemental production gave results for a large region of parameter space in the model of inhomogeneous nucleosynthesis. The inhomogeneous nucleosynthesis produces significant amounts of CNO material at values of $\Omega_{b} \sim 1$ which should be observable as a "cosmic floor" in metal-poor halo stars. Since this result occurs unambiguously for much of parameter space, an observation of primordial $\mathrm{CNO}$ isotopes will be the clearest indication of inhomogeneous nucleosynthesis. Astrophysical observations of $\mathrm{CNO}$ abundances will thus provide an independent probe into this volume of parameter space and allow constraints to be put on the nature of the quark-hadron phase transition.

The ${ }^{7} \operatorname{Li}(n, \gamma){ }^{8} \operatorname{Li}(\alpha, n){ }^{11} \mathrm{~B}(n, \gamma){ }^{12} \mathrm{~B}\left(e^{-} v\right)^{12} \mathrm{C}$ etc, etc channel has proven to be the dominant path to CNO production in regions of parameter space in which there is significant production. This reaction sequence dominates for most values of the fractional volume and the density contrast discussed above at values of $\Omega_{b}$ near 1 . The dominance of this channel is paralleled by $\mathrm{CNO}$ production, thus making observation of significant primordial CNO abundances a clear signal of an inhomogeneous $\Omega_{b} \sim 1$ universe.

CNO abundances in old globular clusters have recently been observed carefully for a variety of reasons. Dickens et al (1991) find that Fe abundance and the sum of the $\mathrm{CNO}$ abundances are the same in red giants in the globular clusters NGC288 and NGC362. However the standard method of age determination using the turn-off point of horizontal branch stars in the clusters indicates that NGC288 is apparently 3 Gyr older than NGC362. The resulting problem is discussed in detail by Silk (1991). Globular clusters are generally thought to have all formed within the freefall collapse time for the Galaxy of 1 Gyr or less. These questions remain but the observed relative abundances are consistent with that expected from the inhomogeneous nucleosynthesis discussed in this article.

Rowan-Robinson et al (1991) find an emission-line galaxy at a redshift of 2.286 with an enormous far-infrared luminosity of $3 \times 10^{14}$ times the 
luminosity of the Sun. A radio-quiet quasar or a starburst imbedded in 1-10 $\times 10^{9}$ solar masses of dust can account for this infrared emission. This large amount of dust in an object of such high redshift implies the generation of heavy elements at an early cosmological epoch. It seems reasonable to the author of this paper that the elements forming this dust were produced in primordial inhomogeneous nucleosynthesis. In any case all those interested in nucleosynthesis in the early universe await further observations of the nature described in these last two paragraphs with great anticipation.

\section{Literature Cited}

Applegate, J. H., Hogan, C. J. 1985. Phys. Rev. D 31: 3037-45

Dickens, R. J., Croke, B. F. W., Cannon, R. D., Bell, R. A. 1991. Nature 351: 212-14

Fowler, W. A. 1984. In Les Prix Nobel en 1983, pp. 83-145. Stockholm: The Nobel Foundation

Kawano, L. H., Fowler, W. A., Kavanagh, R. W., Malaney, R. A. 1991. Ap. J. 372:
Malaney, R. A., Fowler, W. A. 1988. Ap. J. 333: 14-20

Malaney, R. A., Fowler, W. A. 1989. Ap. J. 345: L5-8

Rowan-Robinson, M., Broadhurst, T., Lawrence, A., McMahon, R. G., Lonsdale, C. J., et al. 1991. Nature 351: 719-21

Silk, J. 1991. Nature 351: 191 l-7 
$\overline{\mathrm{A}}$ Annual Review of Astronomy and Astrophysics

R Volume 30,1992

\section{CONTENTS}

From Steam to Stars to the Early Universe, William A. Fowler 1

DUST-Gas INTERACTIONS AND THE INFRARED EMISSION FROM HOT Astrophysical Plasmas, Eli Dwek and Richard G. Arendt 11

WARPS, James J. Binney 51

Astronomical Masers, Moshe Elitzur

Solar Flares and Coronal Mass Ejections, $S$. $W$. Kahler 113

Magnetic Fields of Degenerate Stars, Ganesh Chanmugam 143

The Pluto-Charon Systems, S. A. Stern 185

New Developments in Understanding the HR Diagram, Cesare Chiosi, Gianpaolo Bertelli, and Alessandro Bressan 235

Evidence for Black Holes in Stellar Binary Systems, Anne P. Cowley 287

Cosmological Applications of Gravitational Lensing, R. D. Blandford and R. Narayan 311

Type Ia Supernovae as Standard Candles, David Branch and G. A. Tammann

X-Ray Astronomy Missions, Hale V. D. Bradt, Takaya Ohashi, and Kenneth A. Pounds

The Origin of The X-Ray Background, A. C. Fabian and $X$. Barcons

LONG-Baseline Optical aNd INFraRed STELlar INTERFERometry, M. Shao and M. M. Colavita

The Cosmological Constant, Sean M. Carroll, William H. Press, and Edwin L. Turner

Smoothed Particle Hydrodynamics, J. J. Monaghan

Radio Emission from Normal Galaxies, $J$. $J$. Condon

Evidence for Evolution in Faint Field Galaxy Samples, David C. Koo and Richard G. Kron

ObSERvations of THE Isotropy of the COSMIC Microwave BaCKGround Radiation, Anthony C.S. Readhead and Charles R. Lawrence 